\title{
Morphology alterations of skin and subcutaneous fat at NIR laser irradiation combined with delivery of encapsulated indocyanine green
}

Irina Yu. Yanina

Nikita A. Navolokin

Yulia I. Svenskaya

Alla B. Bucharskaya

Galina N. Maslyakova

Dmitry A. Gorin

Gleb B. Sukhorukov

Valery V. Tuchin 


\title{
Morphology alterations of skin and subcutaneous fat at NIR laser irradiation combined with delivery of encapsulated indocyanine green
}

\author{
Irina Yu. Yanina, ${ }^{a, b, c, *}$ Nikita A. Navolokin, ${ }^{c, d}$ Yulia I. Svenskaya, ${ }^{c}$ Alla B. Bucharskaya, ${ }^{d}$ Galina N. Maslyakova, ${ }^{d}$ \\ Dmitry A. Gorin, ${ }^{c}$ Gleb B. Sukhorukov, ${ }^{c, e}$ and Valery V. Tuchin, ${ }^{a, b, f}$ \\ a Saratov National Research State University, Research-Educational Institute of Optics and Biophotonics, Saratov, Russia \\ ${ }^{b}$ National Research Tomsk State University, Interdisciplinary Laboratory of Biophotonics, Tomsk, Russia \\ 'Educational and Research Institute of Nanostructures and Biosystems, Remote Controlled Theranostic Systems Lab, Saratov, Russia \\ dSaratov State Medical University, Saratov, Russia \\ eQueen Mary University of London, School of Engineering and Materials Sciences, London, United Kingdom \\ IInstitute of the Russian Academy of Sciences, Laboratory of Laser Diagnostics of Technical and Living Systems of Precision Mechanics and \\ Control, Saratov, Russia
}

\begin{abstract}
The goal of this study is to quantify the impact of the in vivo photochemical treatment of rats with obesity using indocyanine green (ICG) dissolved in saline or dispersed in an encapsulated form at NIR laser irradiation, which was monitored by tissue sampling and histochemistry. The subcutaneous injection of the ICG solution or ICG encapsulated into polyelectrolyte microcapsules, followed by diode laser irradiation $\left(808 \mathrm{~nm}, 8 \mathrm{~W} / \mathrm{cm}^{2}, 1 \mathrm{~min}\right)$, resulted in substantial differences in lipolysis of subcutaneous fat. Most of the morphology alterations occurred in response to the laser irradiation if a free-ICG solution had been injected. In such conditions, membrane disruption, stretching, and even delamination in some cases were observed for a number of cells. The encapsulated ICG aroused similar morphology changes but with weakly expressed adipocyte destruction under the laser irradiation. The Cochran $Q$ test rendered the difference between the treatment alternatives statistically significant. By this means, laser treatment using the encapsulated form of ICG seems more promising and could be used for safe layerwise laser treatment of obesity and cellulite. @ 2017 Society of Photo-Optical Instrumentation Engineers (SPIE) [DOI: 10.1117/1.JBO.22.5.055008]
\end{abstract}

Keywords: obesity; cellulite; indocyanine green; polyelectrolyte microcapsules; layer by layer assembly; NIR laser treatment; photochemical action; adipose tissue; histological analysis; cell lipolysis.

Paper 170064PRR received Jan. 27, 2017; accepted for publication May 2, 2017; published online May 25, 2017.

\section{Introduction}

Diabetes, hypertension, heart disease, and early death are obesity complications that are often connected with extra abdominal fat. ${ }^{1-5}$ The fat cell destruction technologies are very important not only to fight against obesity ${ }^{6-17}$ but also to treat cancer (e.g., breast cancer). ${ }^{18-20}$ Adipose tissue usually surrounds the tumor; therefore, it is important to remove fat tissue accurately to ensure optical access to the tumor. ${ }^{21}$ Treatment of breast cancer involves a multimodal approach incorporating surgery (lumpectomy, mastectomy, and/or removal of axillary lymph nodes), chemotherapy, and/or radiation therapy. ${ }^{22-28}$

One of the effective optical methods for the treatment of tumors and other lesions is a combined use of dye such as indocyanine green (ICG) and NIR laser irradiation. ${ }^{29-40}$ ICG is a cyanine dye widely applied in medical diagnostics and surgery for imaging. ${ }^{29-31}$ It is used for determining cardiac output, hepatic function, and liver blood flow and for ophthalmic angiography. ${ }^{31,32}$ It has a peak spectral absorption at 778 to $790 \mathrm{~nm}$ at the monomeric form with a molar absorption coefficient of $10,800 \mathrm{M}^{-1} \mathrm{~cm}^{-1}$, related to the $\pi \rightarrow \pi *$ transition. ${ }^{39,40}$ ICG is usually administered intravenously where it binds tightly to plasma proteins and therefore is confined to the vascular system. Depending on liver performance, it is eliminated from the body exclusively by the liver to bile juice with a halflife of $\sim 3$ to $4 \mathrm{~min}^{38}$

At topical application, the monomeric absorption band of ICG is moved on $\sim 20 \mathrm{~nm}$ to the bigger wavelengths due to binding to tissue proteins, to 805 to $810 \mathrm{~nm}^{37,39,41}$ Therefore, diode lasers with the wavelength of 805 to $810 \mathrm{~nm}$ are suitable for heating and controlling photothermal injury of ICG-stained tissue sites without impacting the surrounding unstained tissue. ${ }^{34-36,42}$ In addition, at light exposure, ICG induces free radicals such as singlet oxygen and end-products of photochemical reactions, which also damage target cells. ${ }^{29,30,39}$ This works particularly well for tumors because they naturally absorb more ICG than healthy tissue. When ICG is injected near tumors, their response to laser light is 2.5 times as much as that of the surrounding tissue. ${ }^{43}$ It is also possible to target specific cells by conjugating the ICG to antibodies. ${ }^{44}$ This method was used to destroy tumors and cancer cells. ${ }^{34,36,45-47}$ In particular, the combination of ICG laser therapy with a triggered immune response provides tumor destruction without future recurrences of cancer. $^{35,36}$

ICG is a problematic dye to work with due to its susceptibility to chemical degradation, nonspecific binding to blood and tissue proteins, and rapid clearance from the body. Thus, it needs to be localized in the target area to minimize these adverse 
effects. Therefore, improved delivery systems to stabilize ICG, such as the use of phospholipid emulsions, polylactic co(glycolic)-acid particles and diblock copolymer micelles, were introduced. ${ }^{48-55}$ ICG-filled biocompatible polyelectrolyte microcapsules are presumed to stabilize the dye and prevent it from immediate interaction with tissue. Microcapsule shells can be formed by a layer-by-layer electrostatic adsorption method using biocompatible polymers. ${ }^{56-59}$

The goal of this work is to quantify the impact of ICG applied in solution or encapsulated into polyelectrolyte microcapsules to provide photochemical treatment of the subcutaneous adipose tissue layer by NIR laser irradiation through rat skin in vivo using follow-up tissue sampling and histology.

\section{Materials and Methods}

\subsection{Laboratory Animals}

A group of 2-year-old female rats totally 20 animals were kept 14 days; besides the standard diet, the rats received $5 \mathrm{~g}$ each of nutrients such as sugar, dry milk, sunflower oil, and egg powder to induce alimentary obesity. Animals were divided into two groups of 10 rats each. Hair was removed within the region of ribs on the back, where treatment was carried out, by the depilation cream Veet (Reckitt Benckiser, France). All procedures with animals were done in accordance with the European Convention for the Protection of Animals used for experimental and other scientific purposes. ${ }^{60}$ The experimental study was conducted in the Centre of Collective Use of Saratov State Medical University (Russia) and according to the guidelines of the University's Animal Ethics Committee (Russia) and the relevant national agency regulating experiments with animals.

\subsection{Agents}

\subsubsection{Dye}

Saline solution of ICG (SIGMA-ALDRICH Co., Germany) of concentration $0.5 \mathrm{mg} / \mathrm{ml}$ was used for fat tissue staining. The solution was kept for 1 to $2 \mathrm{~h}$ before use.

\subsubsection{Capsule preparation and characterization}

ICG (SIGMA-ALDRICH Co., Germany) was encapsulated into degradable polyelectrolyte microcapsules fabricated by a layerby-layer assembly technique. There are a number of studies indicating that degradable polyelectrolyte microcapsules themselves are suitable for subcutaneous drug delivery, since they show a moderate tissue reaction after the injection in mice. ${ }^{61-63}$

The ICG-loaded calcium carbonate $\left(\mathrm{CaCO}_{3}\right)$ microparticles were fabricated using earlier designed technology. ${ }^{57} 1$-ml volumes of $1 \mathrm{M} \mathrm{Na}_{2} \mathrm{CO}_{3}$ and $1 \mathrm{M} \mathrm{CaCl}_{2}$ water solutions were quickly added to $5 \mathrm{ml}$ of $1 \mathrm{mg} / \mathrm{ml}$ ICG water solution in a glass vessel at room temperature and then mixed using the magnetic stirrer Mini MR Standard (IKA, Germany) at $500 \mathrm{rpm}$. The synthesized $\mathrm{CaCO}_{3}$ particles were washed twice with water and then used as templates for microcapsule shell formation. Polyelectrolyte shells were prepared by a self-assembly method using biocompatible degradable polymers (chitosan and dextran sulfate sodium salt) adsorbed layer-by-layer on the templates. The polyelectrolytes were deposited from $1 \mathrm{mg} / \mathrm{ml}$ solutions in $0.15 \mathrm{M} \mathrm{NaCl}$. After each deposition, the suspension was centrifuged for $1 \mathrm{~min}$ at $5000 \mathrm{rpm}$ to separate it into fractions and remove supernatant liquid and then was triply washed with
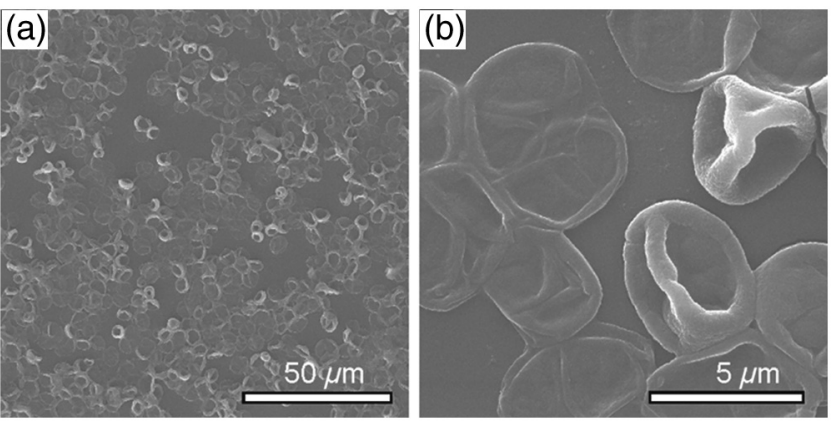

Fig. 1 Scanning electron microscopy images of ICG-loaded polyelectrolyte microcapsules at different magnifications. The microcapsules have a narrow size distribution of $3.5 \pm 0.5 \mu \mathrm{m}$.

water. After consequent deposition of the eight polyelectrolyte layers, $\mathrm{CaCO}_{3}$ templates were dissolved in $2 \mathrm{M}$ ethylenediaminetetraacetic acid and the suspension of microcapsules were triply washed with water, centrifuged at $7000 \mathrm{rpm}$ for $5 \mathrm{~min}$, and re-suspended in $1 \mathrm{ml}$ of saline. Thus, ICG-filled biocompatible degradable polyelectrolyte microcapsules were formed.

To study the morphology and microstructure, a drop of the microcapsule suspension was put on the silicon wafer, dried, sputtered with gold, and imaged with scanning electron microscopes (SEM), a MIRA II LMU (Tescan) at acceleration voltage of $20 \mathrm{kV}$ and a Phillips XL 30 at 5 to $30 \mathrm{kV}$. Performed SEM images of the ICG-loaded polyelectrolyte microcapsules are shown in Fig. 1. The images demonstrate a spherical shape of the capsules and their narrow size distribution of $3.5 \pm 0.5 \mu \mathrm{m}$.

To estimate the ICG concentration in polyelectrolyte containers, the supernatant was collected at each polyelectrolyte deposition and washing step, and the absorption spectrum was examined with a Lambda 950 spectrophotometer (Perkin Elmer). The total amount of loaded molecules was deduced by subtracting the measured amount of unloaded and washed-off molecules of the supernatant from the initial amount of $0.5 \mathrm{mg} / \mathrm{ml}$ of ICG, which had been added to the system. As a measure of the amount of ICG in solution, its optical density spectrum was recorded in the spectral range of 300 to $1000 \mathrm{~nm}$. A calibration curve was obtained from the measurements of known concentrations of ICG in saline.

The resulting concentration of ICG in the saline suspension of obtained microcapsules was found to equal $0.5 \mathrm{mg} / \mathrm{ml}$, meaning $1 \mathrm{pg}$ of ICG per one polyelectrolyte microcapsule.

\subsection{Protocol of Experiment}

The skin sites for each rat with obesity were demarcated into four zones. Each sampling zone was about $1 \mathrm{~cm}$ in diameter. Zone 1 was kept as a control zone without any staining or radiation. For zone 2, subcutaneous dye injection (free ICG or encapsulated ICG, $0.5 \mathrm{mg} / \mathrm{ml}$ ) was performed: the ICG solution was applied to the rats of the first group, while the encapsulated ICG was injected into the rats of the second group. Zone 3 was exposed to radiation from a diode NIR laser (wavelength $808 \mathrm{~nm}$, power density of $8 \mathrm{~W} / \mathrm{cm}^{2}$, exposure of $1 \mathrm{~min}$ ). For zone 4, free ICG or encapsulated ICG injection of the same volume and concentration was followed by light irradiation. Anesthesia of rats was carried out with Zoletil (Vibrac, France). After $1 \mathrm{~h}$ elapsed since the 1-min light exposure, the rats were decapitated. The design of the experiment was compiled on the 
basis of the Guide for the Care and Use of Laboratory Animals. $^{64}$

\subsection{Histology}

For histological studies, samples of skin with subcutaneous tissue of thickness 1.5 to $2.5 \mathrm{~mm}$ were taken by surgery from rats within the marked four-zones of the skin site. For histological examination of excised tissue samples, fixation was carried out by a $10 \%$ solution of formaldehyde. After fixation, the 5- to $7-\mu \mathrm{m}$-tissue slices across all layers of subcutaneous tissue were made, stained by hematoxylin-eosin using a standard technique, and then analyzed. ${ }^{65}$ Morphological study was conducted independently by two experts in the field of pathological anatomy: one is a well-experienced postgraduate student and the other is a professor, doctor of medical sciences. Thus, the study was suited to a double-blind manner.

\subsection{Statistical Data Analysis}

Statistical data analysis was performed using the "Statistics 6.0." In the cases where the indication under study is not characterized by quantitative and qualitative variables, such as serial numbers, indices, signs "+” or “-” (binary scoring system), and so on, only nonparametric methods are possible. The scale of evaluation was dichotomous: any changes in subcutaneous adipose tissue were either present $(=1)$ or not $(=0)$ in the histological samples. The Cochran $Q$-test, a nonparametric test usually applied to the analysis of two-way randomized block designs where the response variable can take only two possible outcomes (coded as 0 and 1), was used. ${ }^{66}$ The test provides a quick recognition of whether $k$ treatments have identical effects. It shows that the empirically found difference between the treatment alternatives is statistically significant.

\section{Results and Discussion}

\subsection{Histological Analysis of Control Samples}

The samples were skin slices with a layer of subcutaneous adipose tissue. In the control samples (zone 1), no changes in the epidermis, dermis, and subcutaneous adipose tissue [Fig. 2(a)] were found. The epidermis is normally thin, and its cells do not have any degenerative changes. The dermis is represented by collagen fibers distributed in different areas and located close to each other. The contours of the fat cells are distinct. Muscle fibers with distinct cross striation are seen. Skin appendages are not changed.

\subsection{Histological Analysis of the Samples after the Injection of Agent}

For the first group of rats, free ICG dissolved in saline was injected subcutaneously, while for the second group encapsulated ICG was applied. In the samples corresponding to zone 2, i.e., the subcutaneous injection of free-ICG [Fig. 2(b)] or encapsulated ICG [Fig. 2(c)], no essential morphological changes of epidermis and dermis were observed. No destruction of adipose tissue, even weakly expressed, was found. For the first group of rats, fat tissue was presented by cells with thinning and split boundaries of the external environment - the cell membranecytoplasm-fat drop. In the case of encapsulated ICG injection, no damage was noticed either. However, for some samples, delamination of cell membranes was found. This could be explained by the mechanical stress on cells caused by swelling.

According to the literature, a moderate tissue reaction is observed after subcutaneous injection of unloaded degradable polyelectrolyte microcapsules in mice. ${ }^{61,62}$ An acute phase is characterized by recruitment of polymorphonuclear cells, and a more chronic phase is marked with environing of the injection site by fibroblasts during the microsphere phagocytosis.

\subsection{Histological Analysis of the Samples after Irradiation}

For the samples corresponding to zone 3, after NIR diode laser irradiation (power density of $8 \mathrm{~W} / \mathrm{cm}^{2}$ and the exposure of $1 \mathrm{~min}$ ), no significant changes were observed: just a little thinned out areas were found for the epidermis, while edema of the dermis was discovered. The irradiation leads to hyperemia in the hypodermis [Fig. 2(d)] of irradiated sites. Moreover, the signs of damage in adipose tissue were found: the boundary thinned and partly disrupted membranes [indicated by arrows in Fig. 2(e)] had a stretched shape, and membrane delamination was observed in some cases [Fig. 2(e)]. Changes of fat cells during $1 \mathrm{~h}$ of observation were characterized as a destruction process, which could potentially lead to lipolysis or necrosis. ${ }^{67,68}$ NIR laser irradiation may stimulate an increase of permeability of fat cell membranes resulting in release of intracellular fat. The fatty triglycerides may flow out through the disrupted cell membranes into the interstitial space where they gradually pass through the lymphatic drainage system. ${ }^{69}$

\subsection{Histological Analysis of the Samples after the Dye Subcutaneous Injection and Irradiation}

In the samples with subcutaneous injection of the ICG solution and subsequent laser irradiation, definite signs of damage in adipose tissue were observed [Fig. 2(f)]. The epidermis was in a normal state, while a local hemorrhage in the dermis and a moderate infiltration of neutrophils and eosinophils in the hypodermis took place. Edema with swelling of certain muscle fibers was observed in the muscle tissue [Fig. 2(g)]. Adipose tissue had pronounced signs of damage seen as strongly stretched cells. Disrupted membranes [indicated by red arrows in Fig. 2(f)] were also found. The ICG tissue staining via subcutaneous injection and subsequent laser irradiation at a physiological constant temperature lead to the generation of oxygen radicals (superoxide and hydroxyl radicals) that causes a modification of fat cell phospholipid membranes and transmembrane cell lipolysis coming out as cell shape transformations.

In the case of encapsulated ICG-injection, we observed similar changes, but with weakly expressed cell destruction [Fig. 2(h)]. In the course of the photochemical/photothermal reaction, in addition to direct cell lipolysis, cell apoptosis can be induced when the microdamages of the cell membrane reach a critical value or strength. ${ }^{70,71}$ Encapsulated ICG tissue treatment rendered a smaller damaging ability. However, such damages could also lead to cell lipolysis and/or apoptosis. ${ }^{72,73}$

It is important to note that, for the samples used to demonstrate posteffects 2-weeks after laser irradiation of the stained tissue sites, significant changes were observed. Intact adipocytes were not found at the site. The fat tissue layer was completely destroyed, partly eliminated with some remaining necrotic masses, and replaced with connective tissue. 


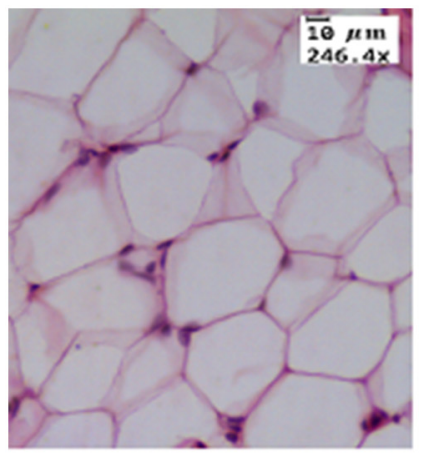

(a)

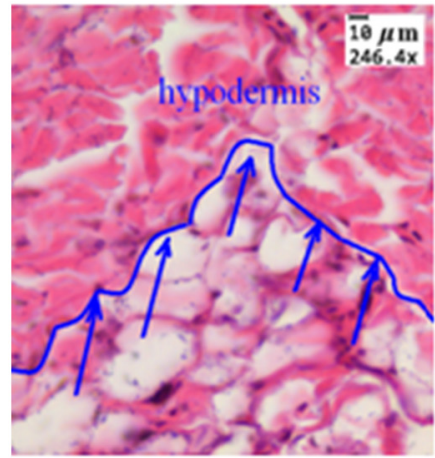

(d)

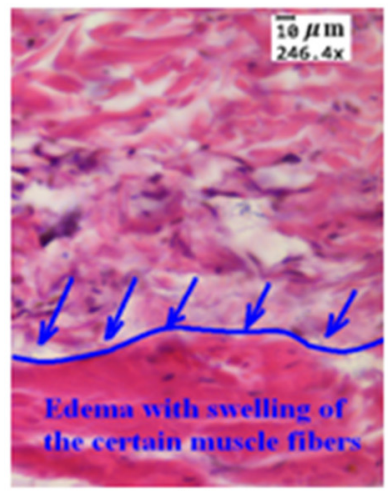

(g)

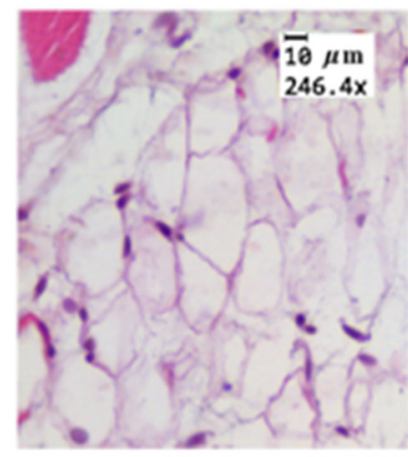

(b)

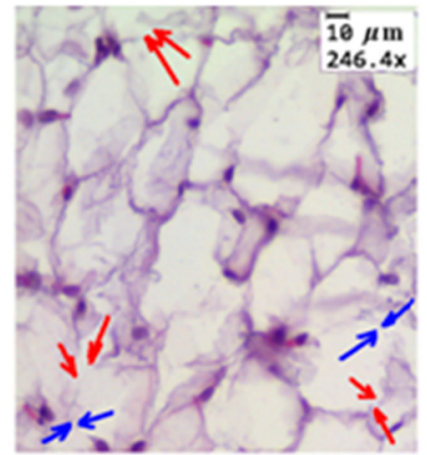

(e)

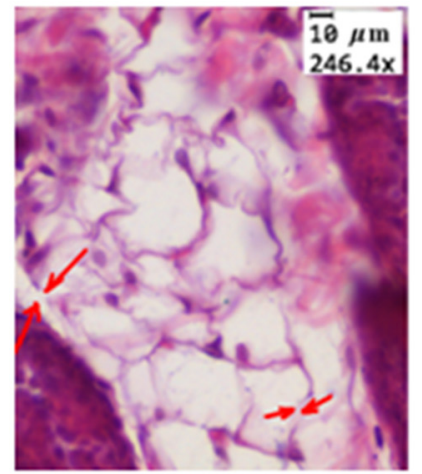

(h)

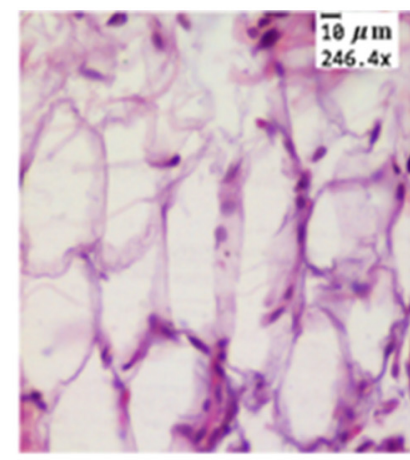

(c)

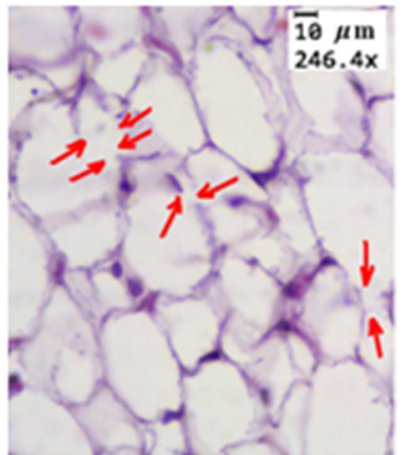

(f)

Fig. 2 Histological (H\&E staining) images of subcutaneous adipose tissue samples taken from in vivo treated rats (magnification 246.4×): (a) no treatment (control); (b) after injection of free-ICG solution $(0.5 \mathrm{mg} / \mathrm{ml}$ in saline); (c) after injection of encapsulated ICG $(0.5 \mathrm{mg} / \mathrm{ml}$ in saline); (d) hyperemia in the hypodermis in zone 3; (e) after 1-min 808-nm diode laser irradiation $\left(8 \mathrm{~W} / \mathrm{cm}^{2}\right)$; (f) after free-ICG injection (ICG $0.5 \mathrm{mg} / \mathrm{ml}$ in saline) and 1-min $808-\mathrm{nm}$ diode laser irradiation $\left(8 \mathrm{~W} / \mathrm{cm}^{2}\right)$; $(\mathrm{g})$ edema with swelling of the certain muscle fibers in zone 4; (h) after encapsulated ICG injection (encapsulated ICG $0.5 \mathrm{mg} / \mathrm{ml}$ in saline) and 1-min 808-nm-diode laser irradiation $\left(8 \mathrm{~W} / \mathrm{cm}^{2}\right)$. Blue arrows-changed (thinned) membranes; red arrows-disrupted membranes.

In our previous work, we investigated photochemical treatment using an ICG solution with a concentration of $1 \mathrm{mg} / \mathrm{ml}$ dissolved in alcohol and 808-nm laser irradiation (power density of $16 \mathrm{~W} / \mathrm{cm}^{2}$ and the exposure time $1 \mathrm{~min}$ ), which caused the pronounced changes in ex vivo adipose tissue accompanied by cell apoptosis and/or necrosis depending on the level of tissue damage. ${ }^{74}$ It was established that application of the free ICGwater solution $(1 \mathrm{mg} / \mathrm{ml})$ or encapsulated ICG-water solution ( $2 \mathrm{mg} / \mathrm{ml})$ as a photochemical dye in the ex vivo experiment increased the cell membrane permeability leading to lipolysis. ${ }^{75}$ For tissue stained by the ICG-water solution, a total lipolysis was seen after 295 min of observation, while for tissue stained by an encapsulated ICG it happened much earlier, after 165-min elapsed. ${ }^{75}$

In our previous work, we found that photochemical treatment in rats in vivo at subcutaneous injection of the ICG solution $(0.5 \mathrm{mg} / \mathrm{ml}$ in saline or in alcohol mixture $)$ and follow-up 808 -nm-diode laser irradiation $\left(16 \mathrm{~W} / \mathrm{cm}^{2}\right.$ and 1 -min exposure) caused the development of pronounced changes in tissue morphology. ${ }^{76}$

In the current study, the biopsy specimens for histology were taken 60 min after light exposure when only the first signs of cell damage and lipolysis occurred. This experiment rendered the encapsulated form of ICG more effective (see Table 1) and 
Table 1 Statistics for the modification appearance in subcutaneous adipose tissue determined from histological studies of rat skin sites at different treatments in vivo.

\begin{tabular}{|c|c|c|c|c|c|c|}
\hline \multirow[b]{2}{*}{$\begin{array}{l}\text { Animal } \\
\text { number }\end{array}$} & \multirow[b]{2}{*}{$\begin{array}{l}\text { Zone } 1 \\
\text { control }\end{array}$} & \multicolumn{2}{|c|}{ Zone 2 (dye) } & \multirow[b]{2}{*}{$\begin{array}{c}\text { Zone } 3 \\
\text { (laser) }\end{array}$} & \multicolumn{2}{|c|}{$\begin{array}{c}\text { Zone } 4 \\
\text { (dye and laser) }\end{array}$} \\
\hline & & $\begin{array}{l}\text { Free } \\
\text { ICG }\end{array}$ & $\begin{array}{l}\text { Encapsulated } \\
\text { ICG }\end{array}$ & & $\begin{array}{l}\text { Free } \\
\text { ICG }\end{array}$ & $\begin{array}{c}\text { Encapsulated } \\
\text { ICG }\end{array}$ \\
\hline 1 & 0 & 1 & 1 & 1 & 1 & 1 \\
\hline 2 & 0 & 1 & 1 & 1 & 1 & 1 \\
\hline 3 & 0 & 0 & 0 & 0 & 1 & 1 \\
\hline 4 & 0 & 0 & 1 & 1 & 1 & 1 \\
\hline 5 & 0 & 0 & 0 & 0 & 0 & 1 \\
\hline 6 & 0 & 1 & 1 & 1 & 1 & 1 \\
\hline 7 & 0 & 0 & 0 & 1 & 1 & 1 \\
\hline 8 & 0 & 1 & 1 & 1 & 1 & 1 \\
\hline 9 & 0 & 0 & 0 & 0 & 0 & 0 \\
\hline 10 & 0 & 0 & 1 & 1 & 1 & 1 \\
\hline $\begin{array}{l}\% \text { of } \\
\text { cases }\end{array}$ & $0 \%$ & $40 \%$ & $60 \%$ & $70 \%$ & $80 \%$ & $90 \%$ \\
\hline
\end{tabular}

promising due to the ability to control cell lipolysis more smoothly and to avoid the unwanted effects of necrosis.

The Cochran $Q$ test can be used to evaluate the relation between two variables that are measured on a nominal scale. One of the variables may consist of only two possible values (dichotomous scale). In our case, six different treatments for 10 laboratory animals were evaluated. The scale of evaluation was dichotomous: any changes in subcutaneous adipose tissue either were present $(=1)$ or not $(=0)$ in the histological samples.

The value of $Q$ becomes greater if there is a statistical association between the variables. If there is no association and only chance is operating, $Q$ reaches exactly the same values as Chi squared $\left(\chi^{2}\right.$-distribution). The degree of freedom equals $(k-1)$, where $k$ is the number of cases or treatments; thus, for our study we have the degree of freedom $=5$. On the basis of data presented in Table 1 , the $Q$ value of 27.6 was calculated using the "Statistics 6.0" program. It is known that results would be significant when $Q$ has a higher value than 15.09 for a significance level $p=0.01{ }^{66}$ Therefore, the Cochran $Q$ test shows that the empirically found difference between the treatment alternatives is statistically significant because in our case $Q>15.09$.

Thus, the combined treatment with the encapsulated ICG dye and the 808-nm laser (last column in the Table 1) is more effective in comparison with the other treatments. The level of significance of such a conclusion is rather high, $p=0.01$.

\section{Conclusion}

Based on the analysis of the results of the histology of tissue samples taken from the in vivo ICG-stained subcutaneous tissue after NIR laser treatment, we came to the following conclusion. The greatest changes without necrosis were observed in the case of combined action of the injection of the free ICG and 808-nm laser irradiation. For some cells, the membrane was partly disrupted, the cells had a stretched shape, and cell membrane delamination was observed in some cases. For the encapsulated ICG application, we observed similar changes with weakly expressed destructive changes of tissue structures and forms of adipocytes without disruption of the cell membrane. The Cochran $Q$ test showed that the empirically found difference between the treatment alternatives is statistically significant, since $Q>Q_{\text {critical }}\left(Q=27.6, Q_{\text {critical }}=15.09\right)$. Therefore, laser treatment using the encapsulated ICG came out as a more effective method in comparison with the free-ICG injection protocol. The significance of the conclusion is rather high, $p=0.01$.

We hypothesize that light irradiation of ICG-stained cells may lead to an increase of fat cell lipolytic activity (the enhancement of lipolysis of cell triglycerides due to the expression of lipase activity and cell release of free fat acids due to temporal cell membrane porosity), and cell elimination due to apoptosis is caused by the induced fat cell stress and/or limited cell necrosis. The obtained data can be used for safe laser treatment of obesity and cellulite.

\section{Disclosures}

All authors have no financial interest.

\section{Acknowledgments}

The authors thank Dr. S. V. Eremina (Department of English and Intercultural Communication of Saratov National Research State University) for the help in manuscript translation to English. This study was supported in part by the government of the Russian Federation (Grant No. 14.Z50.31.0004) (I.Yu. Y., Yu.I.S., N.A.N., A.B.B., G.N.M., D.A.G., G.B.S., V.V.T.) to support scientific research projects implemented under the supervision of leading scientists, Russian Presidential grant for support of young researchers No. MK-6009.2016.2 (I.Yu. Y.) and Russian Presidential Grant NSh-7898.2016.2 (V.V.T. and I.Yu.Y.).

\section{References}

1. L. F. Van Gaal, I. L. Mertens, and C. E. De Block, "Mechanisms linking obesity with cardiovascular disease," Nature 444, 875-880 (2006).

2. C. S. Fox et al., "Abdominal visceral and subcutaneous adipose tissue compartments association with metabolic risk factors in the Framingham heart study," Circulation 116, 39-48 (2007).

3. B. L. Wajchenberg, "Subcutaneous and visceral adipose tissue: their relation to the metabolic syndrome," Endocr. Rev. 21(6), 697-738 (2011).

4. P. K. Myint et al., "Body fat percentage, body mass index and waist-tohip ratio as predictors of mortality and cardiovascular disease," Heart 100, 1613-1619 (2014).

5. N. J. Alvey, "Association of fat density with subclinical atherosclerosis," J. Am. Heart Assoc. 3, e000788 (2014).

6. A. Goldman, D. E. Schavelzon, and G. S. Blugerman, "Laser lipolysis: liposuction using Nd-YAG laser," Rev. Soc. Bras. Cir. Plast. 17, 17-26 (2002).

7. A. Zulmira et al., "Analysis of laser lipolysis effects on human tissue samples obtained from liposuction," Aesthetic Plast. Surg. 29 (4), 281-286 (2005).

8. K. H. Kim and R. G. Geronemus, "Laser lipolysis using a $1064 \mathrm{~nm} \mathrm{Nd:}$ YAG laser," Dermatol. Surg. 32, 241-248 (2006).

9. M. Lukac et al., "QCW pulsed Nd:YAG 1064 nm laser lipolysis," J. Laser Health Acad. 4(1), 1-12 (2009).

10. G. B. Altshuler et al., "Extended theory of selective photothermolysis," Laser Surg. Med. 29, 416-432 (2001). 
11. R. R. Anderson et al., "Selective photothermolysis of lipid a rich tissues: a free electron laser study," Laser Surg. Med. 38, 913-919 (2006).

12. M. Wanner et al., "Effects of noninvasive, $1210 \mathrm{~nm}$ laser exposure on adipose tissue: results of a human pilot study," Laser Surg. Med. 41, 401-407 (2009).

13. M. A. Adatto, R. M. Adatto-Neilson, and G. Morren, "Reduction in adipose tissue volume using a new high-power radiofrequency technology combined with infrared light and mechanical manipulation for body contouring," Laser Med. Sci. 29 (5), 1627-1631 (2014).

14. R. A. Weiss, "Noninvasive radio frequency for skin tightening and body contouring," Semin. Cutan. Med. Surg. 32, S9-S12 (2013).

15. R. S. Mulholland and M. Kreindel, "Non-surgical body contouring: introduction of a new non-invasive device for long-term localized fat reduction and cellulite improvement using controlled, suction coupled, radio frequency heating and high voltage ultra-short electrical pulses," J. Clin. Exp. Derm. Res. 3, 157 (2012).

16. G. A. Ferraro et al., "Synergistic effects of cryolipolysis and shock waves for noninvasive body contouring," Aesth. Plast. Surg. 36(3), 666-679 (2012).

17. V. V. Tuchin et al., "Fat tissue staining and photodynamic/photothermal effects," Proc. SPIE 7563, 75630V (2010).

18. L. M. Morimoto et al., "Obesity, body size, and risk of postmenopausal breast cancer: the Women's Health Initiative (United States)," Cancer Causes Control 13, 741-751 (2002).

19. M. Protani, M. Coory, and J. H. Martin, "Effect of obesity on survival of women with breast cancer: systematic review and meta-analysis," Breast Cancer Res. Treat. 123(3), 627-635 (2010).

20. D. P. Rose, D. Komninou, and G. D. Stephenson, "Obesity, adipocytokines, and insulin resistance in breast cancer," Obes. Rev. 5(3), 153-165 (2004).

21. Y.-F. Zhou, "High intensity focused ultrasound in clinical tumor ablation," World J. Clin. 2(1), 8-27 (2011).

22. K. L. Maughan, M. A. Lutterbie, and P. S. Ham, "Treatment of breast cancer," Am. Fam. Phys. 81(11), 1339-1346 (2010).

23. N. V. B. Renato and N. Paola, "New targeted therapies against breast cancer," J. Carcinogene Mutagene 1, 110 (2010).

24. D. M. McClatchy, III et al., "Molecular dyes used for surgical specimen margin orientation allow for intraoperative optical assessment during breast conserving surgery," J. Biomed. Opt. 20(4), 040504 (2015).

25. D. E. Wazer, "Measuring the value of radiotherapy in older women with breast cancer," J. Clin. Oncol. 30 (23), 2809-2811 (2012).

26. K. B. Clough et al., "Oncoplastic techniques allow extensive resections for breast-conserving therapy of breast carcinomas," Ann. Surg. 237(1), 26-34 (2003).

27. H. Bartelink et al., "Impact of a higher radiation dose on local control and survival in breast-conserving therapy of early breast cancer: 10-year results of the randomized boost versus no boost EORTC 22881-10882 trial," J. Clin. Oncol. 25(22) 3259-3265 (2007).

28. S. Darby et al., "Effect of radiotherapy after breast-conserving surgery on 10-year recurrence and 15-year breast cancer death: meta-analysis of individual patient data for 10, 801 women in 17 randomized trials," Lancet 378, 1707-1716 (2011).

29. J. T. Alander et al., "A review of indocyanine green fluorescent imaging in surgery," Int. J. Biomed. Imaging 2012, 940585 (2012).

30. J. T. Alander et al., "Review of indocyanine green imaging in surgery," in Fluorescence Imaging for Surgeons: Concepts and Applications, F. D. Dip et al., Eds., pp. 35-53, Springer International Publishing Switzerland, New York (2015).

31. D. Grosenick, H. Wabnitz, and B. Ebert, "Review: recent advances in contrast-enhanced near infrared diffuse optical imaging of diseases using indocyanine green," J. Near Infrared Spectrosc. 20 (1), 203-221 (2012).

32. Y. Nishiyama et al., "Endoscopic indocyanine green video angiography in aneurysm surgery: an innovative method for intraoperative assessment of blood flow in vasculature hidden from microscopic view," J. Neurosurg. 117(2), 302-308 (2012).

33. N. Topaloglu et al., "Antibacterial photodynamic therapy with $808-\mathrm{nm}$ laser and indocyanine green on abrasion wound models," J. Biomed. Opt. 20(2), 028003 (2015).

34. G. Shafirstein et al., "Indocyanine green enhanced near-infrared laser treatment of murine mammary carcinoma," Int. J. Cancer 130(5), 1208-1215 (2012).
35. W. R. Chen et al., "Chromophore-enhanced laser-tumor tissue photothermal interaction using an 808-nm diode laser," Cancer Lett. 88, 15-19 (1995).

36. W. R. Chen et al., "Photothermal effects on murine mammary tumors using indocyanine green and an 808-nm diode laser: an in vivo efficacy," Cancer Lett. 98, 169-173 (1996).

37. I. Yu. Yanina et al., "Absorption spectra of photosensitized human fat tissue," Opt. Spectrosc. 109(2), 217-224 (2010).

38. "NCI Drug Dictionary," http://www.cancer.gov/publications/dictionaries/ cancer-drug?cdrid=540122 (2 October 2016).

39. S. Fickweiler et al., "Indocyanine green: intracellular uptake and phototherapeutic effects in vitro," J. Photochem. Photobiol. B Biol. 38, 178-183 (1997).

40. K. Urbanska et al., "Indocyanine green as a prospective sensitizer for photodynamic therapy of melanomas," Acta Biochim. Pol. 49(2) 387-391 (2002).

41. V. V. Tuchin et al., "A pilot study of ICG laser therapy of acne vulgaris: photodynamic and photothermolysis treatment," Lasers Surg. Med. 33(5), 296-310 (2003).

42. I. Yu. Yanina et al., "Optical image analysis of fat cells for indocyanine green mediated near-infrared laser treatment," Laser Phys. Lett. 8(9), 350-359 (2011).

43. X. Li et al., "Tumor localization using fluorescence of indocyanine green (ICG) in rat models," Proc. SPIE 2389, 789 (1995).

44. M. Ogawa et al., "In vivo molecular imaging of cancer with a quenching near-infrared fluorescent probe using conjugates of monoclonal antibodies and indocyanine green," Cancer Res. 69(4), 1268-1272 (2009).

45. L. Bromwell, "Innovative laser therapy offers new hope for breast cancer patients," http://www.lifeextension.com/Magazine/2012/11/ Innovative_Laser_Therapy/Page-01 (2 October 2016).

46. W. R. Chen, "Photoimmunotherapy for cancer treatment," J. Environ. Pathol. Toxicol. Oncol. 25(1-2), 281-292 (2006).

47. W. Tseng et al., "Infrared laser activation of indocyanine green inhibits growth in human pancreatic cancer," Pancreas 27(3), e42-e45 (2003).

48. A. Schönbächler et al., "Indocyanine green loaded biocompatible nanoparticles: stabilization of indocyanine green (ICG) using biocompatible silica-poly(e-caprolactone) grafted nanocomposites," J. Photochem. Photobiol. A Chem. 261, 12-19 (2013).

49. V. B. Rodriguez et al., "Encapsulation and stabilization of indocyanine green within poly(styrene-alt-maleic anhydride) block-poly(styrene) micelles for near-infrared imaging," J. Biomed. Opt. 13(1), 014025 (2008).

50. S. Zanganeh et al., "Enhanced fluorescence diffuse optical tomography with indocyanine green-encapsulating liposomes targeted to receptors for vascular endothelial growth factor in tumor vasculature," J. Biomed. Opt. 18(12), 126014 (2013).

51. T. Toyota et al., "Near-infrared-fluorescence imaging of lymph nodes by using liposomally formulated indocyanine green derivatives," Bioorg. Med. Chem. 22(2), 721-727 (2014).

52. A. Fernandez-Fernandez et al., "Covalent IR820-PEG-diamine nanoconjugates for theranostic applications in cancer," Int. J. Nanomed. 9, 4631-4648 (2014).

53. J. Zhong and S. Yang, "Contrast-enhanced photoacoustic imaging using indocyanine green-containing nanoparticles," J. Innovative Opt. Health Sci. 7(1), 1350029 (2014).

54. J. Zhong et al., "In vivo photoacoustic therapy with cancer-targeted indocyanine green-containing nanoparticles," Nanomedicine $\mathbf{8}(6)$, 903-919 (2013).

55. X. Zheng et al., "Indocyanine green-containing nanostructure as near infrared dual-functional targeting probes for optical imaging and photothermal therapy," Mol. Pharmaceutics 8(2), 447-456 (2011).

56. E. Donath et al., "Novel hollow polymer shells by colloid-templated assembly of polyelectrolytes," Angew. Chem. Int. Ed. 37(37), 22012205 (1998).

57. G. B. Sukhorukov et al., "Porous calcium carbonate microparticles as templates for encapsulation of bioactive compounds," J. Mater. Chem. 14, 2073-2081 (2004).

58. Yu. I. Svenskaya et al., "Calcium carbonate microparticles containing a fotosens photosensitizer: preparation, ultrasound stimulated dye release, and in vivo application," Nanotechnol. Russ. 9(7-8), 398-409 (2014). 
59. E. A. Genina et al., "In vivo optical monitoring of transcutaneous delivery of calcium carbonate microcontainers," Biomed. Opt. Express 7(6), 2082-2087 (2016).

60. D. W. Straughan, "First European Commission report on statistic of animal use," Altern. Lab. Anim. 22, 289-292 (1994).

61. C. Picart, F. Caruso, and J. C. Voegel, Layer-by-Layer Films for Biomedical Applications, John Wiley \& Sons, New York (2014).

62. S. De Koker et al., "In vivo cellular uptake, degradation, and biocompatibility of polyelectrolyte microcapsules," Adv. Funct. Mater. 17(18), 3754-3763 (2007).

63. C. Picart et al., "Controlled degradability of polysaccharide multilayer films in vitro and in vivo," Adv. Funct. Mater. 15(11), 1771-1780 (2005).

64. National Research Council (US) Committee for the Update of the Guide for the Care and Use of Laboratory Animals, Guide for the Care and Use of Laboratory Animals, National Academies Press, Washington (2011).

65. J. H. Thompson and W. R. Richter, "Hematoxylin-eosin staining adapted to automatic tissue processing," Biotech. Histochem. 35(3), 145-148 (1960)

66. T. Hill and P. Lewicki, Statistics: Methods and Applications: A Comprehensive Reference for Science, Industry, and Data Mining, pp. 381-393, StatSoft, Oklahoma (2006).

67. S. Mordon et al., "Histologic evaluation of laser lipolysis: pulsed 1,064 nm Nd:YAG laser versus CW 980 nm diode laser," Aesthetic Surg. J. 27, 263-268 (2007).

68. K. Ichikawa et al., "Histologic and photonic evaluation of a pulsed Nd: YAG laser for ablation of subcutaneous adipose tissue," Lasers Surg. Med. 36, 43-46 (2005).

69. J. C. McBean and B. E. Katz, "Laser lipolysis: an update," J. Clin. Aesthetic Dermatol. 4(7), 25-34 (2011).

70. N. L. Oleinick, R. L. Morris, and I. Belichenko, "The role of apoptosis in response to photodynamic therapy: what, where, why, and how," Photochem. Photobiol. Sci. 1, 1-21 (2002).

71. A. Matsubara et al., "Photodynamic therapy induces caspase-dependent apoptosis in rat CNV model," Invest Ophthalmol. Vis. Sci. 48(10), 4741-4747 (2007).

72. A. Green et al., "Stimulation of lipolysis by tumor necrosis factor-alpha in 3T3-L1 adipocytes is glucose dependent: implications for long-term regulation of lipolysis," Diabetes 53(1), 74-81 (2004).

73. L. Eiselein et al., "Lipolysis products from triglyceride-rich lipoproteins increase endothelial permeability, perturb zonula occludens- 1 and F-actin, and induce apoptosis," Am. J. Physiol. Heart Circ. Physiol. 292(6), H2745 (2007).

74. I. Yu. Yanina et al., "The morphology of apoptosis and necrosis of fat cells after photodynamic treatment at a constant temperature in vitro," Proc. SPIE 7887, 78870X (2011).

75. I. Yu. Yanina et al., "Effect of bacterial lectin on acceleration of fat cell lipolysis at in vitro diode laser treatment using encapsulated ICG,' Proc. SPIE 8337, 83370F (2012).

76. I. Yu. Yanina et al., "Fat tissue histological study at ICG- mediated photothermal/photodynamic treatment of the skin in vivo," J. Biomed. Opt 17(5), 058002 (2012)

Irina Yu. Yanina received her PhD degree in biophysics from Saratov State University (SSU), Saratov, Russia, in 2013. She has authored 17 papers in peer-reviewed journals and 18 papers in conference proceedings. Since 2010, she has been an associate fellow researcher of Laboratory of Biomedical Optics of Research-Educational Institute of Optics and Biophotonics at SSU. Her research interests include the development of optical methods of fat tissue destructive engineering, photodynamic/photothermal therapy, biomedical optics, drug delivery, spectroscopy and imaging in biomedicine, optical and laser measurements.

Nikita A. Navolokin graduated from the Saratov State Medical University n.a. V.I. Razumovsky in 2013. Since 2014 he has been an assistant of the Department of Pathological Anatomy and researcher in Centre of Collective Use of Saratov State Medical University. He is the author of five patents for inventions and more than 80 scientific publications. His sphere of scientific interests is morphology, oncology, photodynamic/photothermal therapy, biomedical optics, and drug delivery.

Yulia I. Svenskaya received the $\mathrm{PhD}$ in biophysics from Saratov State University (Saratov, Russia) in 2013. She is the author of more than 10 papers in peer-reviewed scientific journals. Since 2014, she has been a senior research associate at Research and Education Institution of Nanostructures and Biosystems at Saratov State University. Her research interests include the synthesis of microand submicron carriers for drug delivery; encapsulation of bioactive molecules; targeted delivery of photosensitizers in photodynamic therapy; transdermal delivery of bioactive compounds for photoand photochemotherapy of skin disorders.

Alla B. Bucharskaya, PhD, is head of the Centre of Collective Use of Saratov State Medical University n.a. V.I. Razumovsky from 2010 to present. She is the author of five patents for inventions and more than 20 papers in peer-reviewed journals. She is a member of the Russian Association of Clinical Cytologists. Her research interests include cytology, morphology, oncology, photodynamic/photothermal therapy, biomedical optics, and nanomedicine.

Galina N. Maslyakova has been a head of the Department of Pathological Anatomy of Saratov State Medical University n.a. V.I. Razumovsky since 2004. Since 2012, she has been director of the Scientific Research Institute of Fundamental and Clinical Urinephrology at Saratov State Medical University. She is the author of 10 patents for inventions and more than 200 scientific publications and the main specialist-morphologist of the Ministry of Health of Saratov region. Her scientific interests are morphology, oncology, uronephrology, and nanomedicine.

Dmitry A. Gorin is the professor at the Department of Nano- and Biomedical Technologies at Saratov State University. He has received his MS degree in physics engineering in 1997, candidate of science in physical chemistry in 2001, Doctor of Science in physical chemistry in 2011. He worked as a researcher in the Max Planck Institute of Colloids and Interfaces, Queen Mary University of London. His current research interest focuses on biophysics, biophotonics, theranostics, physics and chemistry of colloids and interfaces, and smart materials.

Gleb B. Sukhorukov holds chair in biopolymers at School of Engineering and Materials Science, Queen Mary University of London (QMUL). He graduated from the Department of Physics, Lomonosov Moscow State University, and after postdoctoral positions in academia and industry he started his independent research group at Max Planck Institute of Colloids and Interfaces in 2001 with help of Sofja Kovalevskaja Award of Alexander von Humboldt Foundation until he moved to QMUL in 2006. He pioneered research on layerby-layer assembled polyelectrolyte capsules with most research outcome relevant to development of multifunctional drug delivery systems enabling encapsulation of various substances in capsules of defined size with triggered release induced by light, magnetic field and ultrasound. He was named among top-10 world known scientists of Russian origin by Forbes.

Valery V. Tuchin is a professor and head of Optics and Biophotonics at Saratov National Research State University and several other universities and institutions. His research interests include tissue optics, laser medicine, tissue optical clearing, and nanobiophotonics. He is a fellow of SPIE and OSA, has been awarded Honored Science Worker of Russia, SPIE Educator Award, FiDiPro (Finland), Chime Bell Prize of Hubei Province (China), and Joseph W. Goodman Book Writing Award (OSA/SPIE). 